\title{
Lean Office em organizações militares de saúde: estudo de caso do Posto Médico da Guarnição Militar de Campinas
}

\author{
Lean Office in health military organizations: \\ case study in the health center of Campinas
}

\author{
Everton Cesar Seraphim ${ }^{1}$ \\ Íris Bento da Silva ${ }^{2}$ \\ Osvaldo Luis Agostinho²
}

\begin{abstract}
Resumo: O presente artigo apresenta uma aplicação dos conceitos de escritório enxuto no nível institucional na área da prestação de serviços, particularmente no segmento de saúde. Dessa forma será apresentado o caso do posto médico militar da guarnição de Campinas, estado de São Paulo, o qual é subordinado ao Comando da $11^{\mathrm{a}}$ Brigada de Infantaria Leve. Para tanto será mostrado inicialmente um panorama da organização e sua situação gerencial, destacando-se os conflitos existentes. Na sequência será vista a metodologia de Lean Office (Escritório Enxuto) aplicada à solução dos problemas e os resultados obtidos.
\end{abstract}

Palavras-chave: Melhoria contínua. Escritório Enxuto. Qualidade. Excelência.

Abstract: This article presents an aplication of the concepts of lean office at the institutional level in the area of services, particularly in the segment of health. Thus, the case study is the Military Treatment Facility in Campinas, state of São Paulo, which is subordinate to the Command of 11th Light Infantry Brigade. Firstly, an organizational and managerial chart is presented highlighting the existing conflicts. Next, the lean office methodology applied to the solution of those problems and the results obtained are presented.

Keywords: Continuous improvement. Lean Office. Quality. Excellence.

\section{Introdução}

As organizações militares apresentam peculiaridades funcionais, fruto de sua estrutura de gerenciamento verticalizada e de seu vínculo com a administração federal. Têm padrões de funcionamento bem definidos por conta de legislação própria e regulamentos que regem a quase totalidade de suas ações. Os processos que envolvem essas ações, por sua vez, necessitam de um permanente ajustamento em função da constante variação, principalmente, no ambiente externo. Uma cadeia de comando verticalizada, inicialmente, favorece uma remodelagem funcional, quando determina de forma veemente seus desdobramentos, que são necessários para alavancar os resultados obtidos.

Em contrapartida, num segundo momento, as ações efetivas de melhoria ficam comprometidas ao serem limitadas pela cultura organizacional ainda muito conservadora nos níveis intermediários e de execução, que resistem a mudanças em seu ambiente. A situação agrava-se quando entram neste contexto as diferenças de cultura gerencial do pessoal de saúde e dos administradores. Esta foi a dificuldade encontrada no Posto Médico da Guarnição de Campinas (PMGuCas) na gestão de seus processos, sejam os de apoio administrativo (back office - atividades que ocorrem sem contato com o cliente), sejam os finalísticos, voltados ao atendimento (front office - atividades em que o contato com o cliente é alto), os quais, se deseja, que tenham qualidade.

Outro aspecto que dificulta sobremaneira a operacionalidade do Posto é a descentralização das atividades, o que compromete a comunicação, a tomada de decisões e o andamento da maioria dos processos.

\footnotetext{
${ }^{1} 11^{\text {a }}$ Brigada de Infantaria Leve, Exército Brasileiro, Mestrando da Universidade Estadual de Campinas - UNICAMP, E-mail: ecserafa@ig.com.br

${ }^{2}$ Departamento de Engenharia de Fabricação - DEF, Faculdade de Engenharia, Mecânica - FEM, Universidade Estadual de Campinas - UNICAMP, E-mails: iris@ fem.unicamp.br; agostinh@ fem.unicamp.br
}

Recebido em 1/12/2008 — Aceito em 30/3/2010

Suporte financeiro: Nenhum 
Dessa forma, os conceitos do Lean Office (Escritório Enxuto), propostos por Tapping e Shuker (2003), podem apresentar bons resultados para organizações militares de saúde. Esse conceito aprimora o fluxo de trabalho e a eliminação dos desperdícios existentes em áreas administrativas.

O presente artigo pretende apresentar uma aplicação do Escritório Enxuto no nível institucional na área da prestação de serviços, particularmente no segmento de saúde em organizações militares. É importante ressaltar que o Exército Brasileiro desenvolve, há cinco anos, um programa de excelência gerencial para fazer face aos problemas como os que aqui serão citados.

Com base nestes pontos, o desenvolvimento do presente trabalho foi direcionado pelas seguintes perguntas de pesquisa:

P1: Como equacionar as diferenças de cultura gerencial de pessoas da área de saúde com administradores?

P2: É possível reduzir o lead-time em processos administrativos com atividades descentralizadoras?

Este trabalho está estruturado como segue. Inicialmente, na secção 2, apresenta-se o referencial teórico sobre a metodologia Escritório Enxuto e, na secção 3, o método de pesquisa adotado neste trabalho. Em seguida, é apresentado, na secção 4, um estudo de caso de implementação da abordagem enxuta na administração, que, por sua vez, é analisado à luz das perguntas de pesquisa e, finalmente, são apresentadas as conclusões do trabalho.

\section{Referencial teórico: Escritório Enxuto}

\subsection{Conceitos do Escritório Enxuto}

Os princípios enxutos ganharam notoriedade na década de 1980 com a divulgação dos resultados de um projeto de pesquisa conduzido pelo MIT (Massachusetts Institute of Technology) que estudou as práticas gerenciais e os programas de melhorias adotados por empresas líderes de mercado na cadeia de produção automotiva e constatou que a adoção destes princípios em muito contribuiu para sua competitividade (WOMACK; JONES; ROOS, 2001).

O pensamento enxuto, também chamado de Manufatura Enxuta, está apoiado, em princípio, no STP (Sistema Toyota de Produção) (LIKER, 2004; DENNIS, 2007). Ele consiste na redução ou eliminação de desperdícios no processo produtivo, que não agregam valor para o cliente.

Dessa forma, para que os processos administrativos tornem-se enxutos, as empresas já começaram a discutir esta possibilidade. A passagem desta metodologia, da área industrial para o escritório, não é tão simples e ainda encontram-se poucos relatos de experiências reais da abordagem enxuta, na administração das empresas. É muito lógico identificar os desperdícios quando são envolvidos matérias-primas e processos de transformação física (HINES; TAYLOR, 2000; MURGAU; JOHANSSON; PEJRYD, 2006). Porém, nas áreas administrativas, a maioria das atividades é relacionada à geração de informações (atividades de natureza intangível, como exemplo, serviços) o que torna difícil a identificação dos desperdícios, pois visualizar algo intangível como a informação, em fluxo de processos, é bem mais complexo (OLIVEIRA, 2007).

A aplicação dos princípios enxutos nesse caso é chamada de Lean Office (Escritório Enxuto) (TURATI; MUSETI, 2006). O fluxo de valor, nessa forma, consiste no fluxo de informações e de conhecimentos, o qual apresenta maior dificuldade, como já dito, em ter a sua trajetória de valor agregado definida (McMANUS, 2003; PIERCY; RICH, 2009). O objetivo do pensamento relacionado ao Escritório Enxuto é reduzir ou eliminar os desperdícios ligados ao fluxo de informações, uma vez que apenas $1 \%$ das informações geradas agrega valor (HINES; TAYLOR, 2000).

\subsection{Desperdícios no Escritório Enxuto}

Os chamados sete desperdícios, segundo Womack e Jones (2004), são identificados classicamente na manufatura (Quadro 1). Eles também podem ser encontrados no escritório (Quadro 1 e Anexos de 1 a 3). O desperdício no processamento pode ser, por exemplo, o excesso de assinaturas e revisões, em diferentes níveis da organização, em documentos. Esse desperdício, no Escritório Enxuto, provoca o não alinhamento com a visão estratégica de negócios de uma organização.

O desperdício chamado de superprodução pode gerar mais informações em papéis do que é necessário (excesso de papel ou burocratização). O desperdício com estoque pode ser exemplificado como relatórios produzidos em excesso que ficam arquivados nos computadores. O defeito é um desperdício que pode ser dados incorretos registrados (LAREAU, 2002).

O desperdício de transporte é um fluxo de comunicação superior ao demandado. $\mathrm{O}$ de movimentação está associado a um arranjo físico, que leva a um alto volume de circulação entre as áreas. E o de espera, por sua vez, é, por exemplo, um documento aguardando assinatura de um superior que se encontra em viagem (LAREAU, 2002).

\subsection{Transformação enxuta nos escritórios}

A transformação enxuta nos escritórios recomenda determinadas ferramentas de planejamento e de ação. 
Quadro 1. Os sete desperdícios na Manufatura e no Escritório (adaptado de LAREAU, 2002).

\begin{tabular}{|c|c|c|}
\hline Item & Manufatura & Escritório \\
\hline $\begin{array}{l}\text { Processamento } \\
\text { sem valor }\end{array}$ & $\begin{array}{l}\text { Utilização errada de ferramentas, procedimentos } \\
\text { ou sistemas. }\end{array}$ & $\begin{array}{l}\text { Uso incorreto de procedimentos ou sistemas } \\
\text { inadequados, ao invés de abordagens } \\
\text { simples e eficazes }\end{array}$ \\
\hline Superprodução & $\begin{array}{l}\text { Produzir excessivamente ou cedo demais, } \\
\text { resultando excesso de inventário. }\end{array}$ & $\begin{array}{l}\text { Gerar mais informação, em meio eletrônico } \\
\text { ou papéis, além do que se faz necessário ou } \\
\text { antes do correto momento }\end{array}$ \\
\hline Inventário & $\begin{array}{l}\text { Excesso de matéria-prima, de peças em } \\
\text { processamento e estoque final. }\end{array}$ & $\begin{array}{l}\text { Alto volume de informação armazenado } \\
\text { (buffer sobrecarregado) }\end{array}$ \\
\hline Defeito & Problema de qualidade do produto ou serviço. & $\begin{array}{l}\text { Erros frequentes de documentação, } \\
\text { problemas na qualidade dos serviços ou } \\
\text { baixa performance de entrega }\end{array}$ \\
\hline Transporte & $\begin{array}{l}\text { Movimento excessivo de pessoas ou peças, } \\
\text { resultando em dispêndio desnecessário de capital, } \\
\text { tempo e energia. }\end{array}$ & $\begin{array}{l}\text { Utilização excessiva de sistemas } \\
\text { computacionais nas comunicações }\end{array}$ \\
\hline Movimentação & $\begin{array}{l}\text { Desorganização do ambiente de trabalho, } \\
\text { resultando em baixa performance dos aspectos } \\
\text { ergonômicos e perda frequente de itens. }\end{array}$ & $\begin{array}{l}\text { Movimentação excessiva de pessoas e } \\
\text { informações }\end{array}$ \\
\hline Espera & $\begin{array}{l}\text { Longos períodos de ociosidade de pessoas e } \\
\text { peças, decorrentes, por exemplo, de máquina em } \\
\text { manutenção ou em preparação (set-up), resultando } \\
\text { em lead time longo. }\end{array}$ & $\begin{array}{l}\text { Períodos de inatividade das pessoas e } \\
\text { informações (aprovação de assinatura, } \\
\text { aguardar fotocópias, esperar no telefone) }\end{array}$ \\
\hline
\end{tabular}

As ferramentas de maior aplicação no Escritório Enxuto são apresentadas a seguir.

Rother e Shook (2003) preconizam a aplicação do Mapeamento do Fluxo de Valor (VSM - Value Stream Mapping), que é uma ferramenta de planejamento, que facilita a visualização dos fluxos de informações. O VSM procura retratar de uma maneira abrangente o sistema de serviço e visa à construção de mapas que representam, numa mesma página, tanto o fluxo de informação (desde o pedido do cliente até a programação do serviço) como o fluxo de informações (desde a concepção até o serviço entregue) (TAPPING; SHUKER, 2003; PICCHI, 2002; LIMA, A. C., PINSETTA, W. J. M.; LIMA, P. C., 2005).

A ferramenta de ação Cinco Esses (5S) constitui uma prática que é importante tanto para motivar a mudança como para se estabelecer a disciplina e ainda para padronizar. Para isso, cada um dos "esses" considerados promove uma atitude fundamental para a racionalização do trabalho. São eles: Seiri (Organização: "faça o necessário"); Seiton (Ordem: "um lugar para cada coisa, cada coisa em seu lugar"); Seiso (Limpeza: "boa iluminação, baixo ruído, ambiente limpo"); Seiketsu (Padronização: "bons resultados devem ser disseminados"); e Shitsuke (Disciplina: "seguir procedimentos enxutos") (FABRIZIO; TAPPING, 2006). Essa aplicação aliada a um adequado arranjo-físico resulta em melhor controle visual e execução de tarefas de forma enxuta (OLIVEIRA, 2007).
O Fluxo Contínuo permite que as informações possam fluir entre as etapas do processo, com remoção de gargalos, sem paradas, sem estoque de informações (arquivo na informática) e sem pessoas se deslocando entre as etapas. A adequação do espaço de trabalho deve permitir que as pessoas possam se olhar, mutuamente, sem divisórias e se posicionarem na sequência do serviço. Esse fato levará a um aumento de produtividade e redução do lead-time (TAPPING; SHUKER, 2003).

Já o Trabalho Padrão (TP) é a melhor combinação de recursos como colaboradores e equipamentos, para assegurar que uma tarefa seja realizada sempre da mesma forma. Isso significa discutir, estabelecer, documentar e padronizar, por meio de um procedimento, o melhor resultado, com o melhor método. A padronização nos ambientes administrativos gera um fluxo de atividades contínuo, que reduz os gaps na qualidade do serviço; facilitando o treinamento (PICCHI, 2002).

Destaca-se também que autores, como Lewis (2000), Meier e Forrester (2002), e Shah e Ward (2003), que desenvolveram levantamentos sobre as práticas enxutas, que têm sido efetivamente implementados, identificaram dentre outras: teamwork (grupos de trabalho), multifuncionalidade e técnicas de mudanças.

O método normalmente indicado para a implementação enxuta é a realização de workshops kaizen alinhados com o Mapeamento de Fluxo de Valor, que devem ser acompanhados no dia a dia por meio de 
controles visuais (Gestão à Vista ou Radar) (LARAIA; MOODY; HALL, 1999; MANN, 2005).

$\mathrm{O}$ administrador, ao tentar no primeiro impulso aplicar somente kaizens administrativos, fica restrito a uma "ilha isolada", que se inicia e termina num processo particular da organização. Esse fato pode levar ao foco somente estrutural, não sistêmico e muito menos ao estratégico, pois as grandes oportunidades estão nas interfaces, nas entradas e nas saídas, dos processos ao longo do fluxo (AHLSTROM, 2004). Dessa forma, recomenda-se a aplicação de uma visão ampla do enxuto nos escritórios. Para se atingir este estado, Tapping e Shuker (2003), propõe oito passos, apresentados no Quadro 2.

Os sistemas administrativos devem apoiar os fluxos de valor nas relações com clientes, no equacionamento da demanda e da entrega (GEORGE, 2004). Segundo Gil (2001), esses sistemas também devem planejar a gestão estratégica de pessoas (treinamento em conceitos e ferramentas enxutas, desenvolvimento de habilidades multifuncionais, grupos de resolução de problemas, programas de sugestão, dentre outros).

A aplicação dos princípios enxutos na área de serviços é um dos principais desafios do futuro. Reduzir os tempos das atividades nos recursos disponíveis, reduzir falhas e aumentar o valor agregado das operações são os principais objetivos da aplicação dos programas enxutos nos escritórios (TAPPING; SHUKER, 2003; KIM et al., 2006).

Segundo Ehrlich (2002), McPherson e Mitchell (2005) e Miyake e Ramos (2007), as técnicas enxutas melhoram a qualidade dos produtos e serviços, ao mesmo tempo que reduzem desperdícios e custos.

\section{Metodologia}

O objeto de estudo deste artigo é a aplicação da metodologia enxuta em escritório. Ele tem como propósito levantar indicações de como implantar tal iniciativa para se obter efetivamente a redução de desperdícios e de lead-time nos processos administrativos. Dessa forma, o artigo tem como foco proporcionar maior familiaridade com Escritório Enxuto por meio de uma pesquisa que pode ser enquadrada como de natureza exploratória, segundo critérios de classificação fornecidos (MARCONI; LAKATOS, 2002).

Além disso, o trabalho também tem como preocupação, apresentar uma descrição das evidências de aplicação identificadas em um caso especial em serviços nas Organizações Militares de Saúde. Para se atender a este propósito, o método de pesquisa adotado para o desenvolvimento deste trabalho foi o estudo de caso que, segundo Yin (2005)

[...] é uma forma de pesquisa empírica, que visa investigar fenômenos contemporâneos, considerando o contexto real do fenômeno estudado, geralmente quando as fronteiras entre o contexto e o fenômeno não estão bem definidas [...].

Este método geralmente envolve a investigação de um caso e busca a criação de relações e entendimentos sobre o objeto do estudo.

Embora o presente tema tenha atraído as empresas, nota-se que a abordagem escritório enxuto ainda é pouco disseminada entre elas e que são raras as organizações que após terem deslanchado esforços para a sua promoção, conseguiram avançar até concluir uma implantação com sucesso.

Assim, para a realização deste estudo foi selecionada uma organização militar de saúde, que despontou no ranking, no Brasil. Ela foi uma das pioneiras nesta aplicação. Trata-se, portanto de uma experiência organizacional na área de serviços em saúde, que reúne atributos que a qualificam como um caso revelador (YIN, 2005).

Quadro 2. Oito passos para se alcançar o Escritório (adaptado de LAREAU, 2002).

\begin{tabular}{|cl|}
\hline Passo & \multicolumn{1}{c|}{ Descrição } \\
\hline 1 & $\begin{array}{l}\text { Aprendizado e envolvimento enxuto: todos devem ter um bom entendimento } \\
\text { sobre o conceito enxuto. }\end{array}$ \\
2 & $\begin{array}{l}\text { Comprometimento com o enxuto: deve haver comprometimento de todos e o trabalho em equipe deve ser } \\
\text { estimulado. }\end{array}$ \\
3 & $\begin{array}{l}\text { Escolha do fluxo de valor: deve ser escolhido o fluxo de valor do processo mais } \\
\text { representativo na organização. }\end{array}$ \\
4 & $\begin{array}{l}\text { Mapeamento do estado atual: fornece uma clara visão dos desperdícios e mostra o } \\
\text { status atual do processo analisado. }\end{array}$ \\
5 & $\begin{array}{l}\text { Identificação de ferramentas: escolher quais ferramentas ajudarão a alcançar o estado enxuto. } \\
\text { Mapeamento do estado futuro: as propostas de melhorias deverão ser incorporadas ao mapa, considerando-se } \\
7\end{array} \quad \begin{array}{l}\text { Criação do plano kaizen: estabelecer processos, prazos e responsáveis pelas melhorias. } \\
8\end{array} \quad \begin{array}{l}\text { Implementação do plano kaizen: implementar as propostas do mapa futuro com acompanhamento de gestão } \\
\text { à vista ou radar. }\end{array}$ \\
\end{tabular}


O caso estudado foi desenvolvido no Posto de Saúde da Guarnição de Campinas (PMGuCas). A organização de estudo é uma organização militar pertencente ao Exército Brasileiro. A unidade que foi pesquisada localiza-se no Estado de São Paulo e está posicionada entre as líderes de seu segmento.

Para a coleta de dados mais específicos sobre a forma, como o projeto Escritório Enxuto tem sido conduzido no caso estudado, foi selecionada para análise uma amostra do processo de recepção do Posto de Saúde e as correlações entre 17 áreas ligadas ao atendimento. Não se trata de uma amostra probabilística, mas de uma amostra intencional cujo projeto foi selecionado de modo que constituísse um subconjunto representativo da população de projeto em termos de características como: objetivo, escopo e modo de desenvolvimento, uma vez que existem outros Postos de Saúde no Brasil pertencentes ao Exército. A viabilização deste estudo foi por meio do acesso a dados primários e documentação específica sobre a amostra do projeto selecionado.

O caso estudado é apresentado nas próximas seções. Ele procurará responder às duas perguntas de pesquisas apresentadas na introdução deste trabalho.

\section{Estudo de caso: Lean Office aplicado no Posto Médico da Guarnição militar}

\subsection{Sistema de saúde do Exército Brasileiro}

O sistema de saúde do Exército está desdobrado em três níveis: primário, secundário e terciário (Quadro 3). No nível primário estão localizadas as Formações de Saúde (FS) instaladas nas diversas Organizações Militares de Emprego (corpos de tropa) ou de Apoio Geral (arsenais, depósitos, escolas, centros de pesquisa, comandos, campos de instrução, dentre outros) que prestam o apoio de saúde imediato aos seus integrantes, assim como realizam os primeiros procedimentos de controle sanitário da tropa e a triagem dos casos que necessitam de tratamento especializado em organizações de segundo ou terceiro nível.
O nível secundário é ocupado pelas Policlínicas Militares e pelos Postos Médicos de Guarnição (PMGu), instalados em localidades com uma maior concentração de organizações militares. Neste nível funcionam as Juntas de Inspeção de Saúde (JIS), onde são realizadas as perícias médicas em primeira instância. $\mathrm{O}$ atendimento é ambulatorial e não há capacidade para internações ou grandes cirurgias.

Os casos que necessitam de internação ou de tratamento cirúrgico são encaminhados para os Hospitais Militares mais próximos, que caracterizam as Organizações de Saúde de terceiro nível. Neste nível também funcionam as juntas de inspeção de saúde em grau de recurso.

Há ainda a possibilidade, em todos os níveis, por força de alguma especificidade de tratamento ou restrição de alguma especialidade do pessoal de saúde militar da Organização Militar de Saúde, do atendimento em Organizações Civis de Saúde (OCS) ou com Profissionais de Saúde Autônomos (PSA) conveniados.

O sistema é subsidiado com recursos governamentais, particularmente em função do serviço militar obrigatório, assim como, na sua maior parte, com recursos próprios do Fundo de Saúde do Exército, estes captados compulsoriamente de todos os beneficiários do atendimento.

\subsection{Estrutura organizacional do Posto Médico da Guarnição de Campinas}

Na Figura 1, pode-se ver a estrutura da Guarnição Militar de Campinas. Ela contém o Posto Médico da Guarnição de Campinas (PMGuCas), a Escola Preparatória de Cadetes e as Organizações Militares Operacionais da Brigada sediadas na cidade.

O Posto Médico da Guarnição de Campinas é uma Organização Militar de Saúde (OMS) de nível secundário, que concentra toda a atividade de saúde na Guarnição de Campinas.

O Posto Médico é responsável também pela assistência médica a todo o público de militares do Exército, da ativa, da reserva e pensionistas militares e a todos os seus dependentes, residentes na área de Campinas e região, bem como a todos

Quadro 3. Organização Militar de Saúde (OMS).

\begin{tabular}{|llll|}
\hline \multicolumn{2}{c|}{ Militares } & \multicolumn{1}{c|}{ Civis } \\
\hline Nível Primário & $\begin{array}{l}\text { Formações } \\
\text { de Saúde (FS) }\end{array}$ & $\begin{array}{l}\text { Corpos de tropa } \\
\text { Apoio (arsenais, depósitos, } \\
\text { escolas, outros) }\end{array}$ & $\begin{array}{l}\text { Organizações } \\
\text { Civis de Saúde (OCS) }\end{array}$ \\
Nível Secundário & $\begin{array}{l}\text { Postos Médicos } \\
\text { de Guarnição (PMGu) }\end{array}$ & $\begin{array}{l}\text { Instalados em locais de maior } \\
\text { concentração de organizações militares }\end{array}$ & $\begin{array}{l}\text { Profissionais de Saúde } \\
\text { Aível Terciário }\end{array}$ \\
& $\begin{array}{l}\text { Hospitais } \\
\text { Militares (HM) }\end{array}$ & $\begin{array}{l}\text { Internação } \\
\text { Tratamentos cirúrgicos }\end{array}$ & \\
\hline
\end{tabular}


os beneficiários do Fundo de Saúde do Exército (FuSEx) em circunstâncias especiais, tais como urgências ou emergências. Este universo alcança um total aproximado de 6 mil usuários. Em caráter especial também são atendidos militares da Marinha e Aeronáutica e seus dependentes.

A estrutura física dispõe de uma área construída de aproximadamente $600 \mathrm{~m}^{2}$, que se destina ao atendimento médico, odontológico, laboratorial e de enfermagem em nível ambulatorial, integrados pela Divisão de Saúde, além de toda a administração do sistema de saúde, realizados pela Divisão do FuSEx e de perícias médicas, realizados pela Junta de Inspeção de Saúde de Guarnição, coordenadas pela Seção de Perícias Médicas.

Na atividade da Divisão de Saúde, o Posto Médico dispõe de cinco consultórios médicos que atendem nas áreas de clínica médica, cardiologia, ginecologia e obstetrícia, pediatria, cirurgia, ortopedia, pneumologia e dermatologia em regime de rodízio. Possui ainda, uma sala de pronto atendimento, uma sala de observação, uma área destinada ao Serviço de Arquivo Médico e Estatística, um Laboratório de Análises Clínicas que atua nas áreas de hematologia, bioquímica e parasitologia e quatro gabinetes odontológicos com atuação nas áreas de dentisteria, periodontia, endodontia, cirurgia oral e prótese odontológica. Estas atividades funcionam em horário comercial. Há um regime de pronto atendimento médico e odontológico que funciona ininterruptamente em regime de plantão.

A Divisão FuSEx (Fundo de Saúde do Exército) executa, a administração e o atendimento das atividades de responsabilidade da Unidade Gestora da $11^{\text {a }}$ Brigada de Infantaria Leve (UG/FuSEx $11^{\mathrm{a}}$ Bda Inf L), por meio das Seções de Contrato e Credenciamento; de Auditoria de Contas Médicas; de Averbação,
Pagamento e Ressarcimento de Despesas; de Aquisição de Próteses, que funcionam em horário comercial; e da Seção de Triagem e Emissão de Guias de Encaminhamento, que tem funcionamento ininterrupto em regime de plantão. A Seção de Perícias Médicas dispõe de uma sala para a administração e uma sala para exame médico e funciona às segundas, quartas e sextas-feiras em horário comercial.

O Fundo de Saúde do Exército (FuSEx) é um sistema de saúde suplementar que garante a disponibilização de assistência médica aos seus usuários, seja ela realizada com recursos próprios ou contratada no sistema de saúde privado. Para esta finalidade, todo titular do FuSEx contribui mensalmente com um percentual de seus vencimentos. Sempre que necessitar usar o sistema, o beneficiário arcará com $20 \%$ de todas as despesas realizadas, as quais são indenizadas ao Fundo de Saúde, mediante o desconto mensal em folha, no valor de até $10 \%$ de seus vencimentos. Dessa forma, todo beneficiário do FuSEx é corresponsável em suas despesas. As despesas de cada beneficiário são implantadas no sistema por meio da seção de averbação da UG/FuSEx (Unidade Gestora do Fundo de Saúde do Exército), eletronicamente.

Para tanto o Posto Médico conta, em seus quadros, de forma fixa, com trinta oficiais $(90 \%$ na atividade fim e $10 \%$ em atividade meio) e vinte e três graduados entre sargentos, cabos e soldados, em sua totalidade, realizando atividades de apoio administrativo.

\subsection{Sistemas corporativos de apoio ao Posto Médico}

Os sistemas corporativos de apoio aos órgãos de saúde do Exército (Anexo 4) são ferramentas de tecnologia da informação (TI) colocadas à disposição

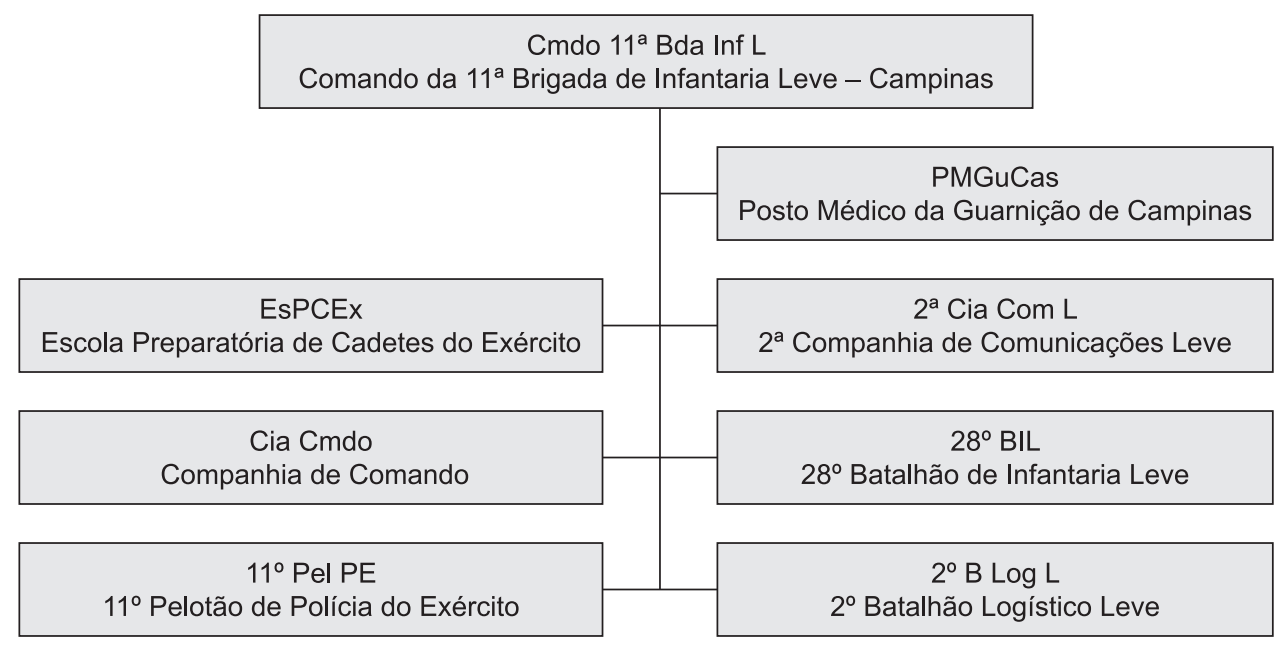

Figura 1. Organização da Guarnição Militar de Campinas. 
para viabilizar, com oportunidade e agilidade, as tarefas de gestão em todos os níveis.

Todas as atividades desenvolvidas pelo Posto Médico são gerenciadas por sistemas eletrônicos de tempo real, integrados no SIGIR (Sistema Integrado de Gestão Inteligente de Recursos), no SIPEO (Sistemas Públicos de Planejamento e Execução Orçamentária) e no SIAFI (Sistema de Administração e de Fiscalização de Pagamento). A descrição desses sistemas está no Quadro 4.

Esses sistemas gerenciam, por exemplo, os atendimentos realizados pela Organização Militar de Saúde (OMS), nesse caso o Posto Médico, que envolvem gastos de materiais e medicamentos, os quais são indenizados pelo usuário na mesma proporção de $20 \%$, tal como ocorre nos atendimentos realizados pelas OCS (Organizações Civis de Saúde) e PSA (Profissionais de Saúde Autônomos). Estes recursos retornam para a OMS que os utilizam, para a reposição dos materiais e medicamentos, de acordo com sua necessidade.
Além disso, as atividades da Divisão de FuSEx são gerenciadas por um sistema denominado FIGOMIS (Ficha de Informação Gerencial das Organizações Militares de Saúde); pelo SISGEMS (Sistema de Gestão do Estoque de Material de Saúde) e pelo SISPMED (Sistema de Perícias Médicas).

O sistema SIRC (Sistema de Registro de Contratos) administra as OCS (Organizações Civis de Saúde) e PSA (Profissionais de Saúde Autônomos). Esses sistemas estão descritos no Quadro 5.

No SISGEMS, a gestão da aquisição, controle do estoque, distribuição, aplicação e cobrança desses produtos, é gerenciada de forma integrada entre o SIRE, o SIPEO e o SIAFI. O SISGEMS embora integrado ao SIGIR, não possui interface com os demais. À exceção do SISPMED, todos os demais sistemas são integrados e cruzam informações entre si e com o SIPEO (Sistemas Públicos de Planejamento e Execução Orçamentária) e o SIAFI (Sistema de Administração e de Fiscalização de Pagamento).

Quadro 4. Sistemas corporativos de apoio: SIGIR, SIPEO e SIAFI.

\begin{tabular}{|ll|}
\hline \multicolumn{1}{|c|}{ Sistema } & \multicolumn{1}{c|}{ Descrição } \\
\hline SIGIR & Este sistema gerencia todas as atividades do Posto Médico \\
Sistema Integrado de Gestão & por meio de sistemas eletrônicos em tempo real. Utiliza a \\
Inteligente de Recursos & administração pela qualidade e excelência gerencial. \\
SIPEO & Este sistema gerencia a descentralização de recursos para \\
Sistemas Públicos de Planejamento e & atender às ações finalísticas do departamento pessoal. \\
Execução Orçamentária & \\
SIAFI & Este sistema gerencia os pagamentos. \\
Sistemas de Administração e de & \\
Fiscalização de Pagamento & \\
\hline
\end{tabular}

Quadro 5. Sistemas corporativos de apoio: SIRC, SISPMED, SISGEMS e FIGOMIS.

\begin{tabular}{|c|c|}
\hline Sistema & Descrição \\
\hline $\begin{array}{l}\text { SIRC } \\
\text { Sistema de Registro de Contratos }\end{array}$ & $\begin{array}{l}\text { Este sistema permite o cadastro das OCS e PSA para a realização dos } \\
\text { encaminhamentos. Para o cadastro são necessários vários procedimentos } \\
\text { prévios atendendo a todos os preceitos da Lei de Licitações e Contratos. }\end{array}$ \\
\hline $\begin{array}{l}\text { SISPMED } \\
\text { Sistema de Perícias Médicas }\end{array}$ & $\begin{array}{l}\text { Este sistema controla as perícias médicas, incluindo o agendamento, a } \\
\text { inspeção, o resultado, bem como a emissão de todos os documentos, tais } \\
\text { como Ficha de Registro de Inspeção de Saúde, Livro de Registro de Atas } \\
\text { de Inspeção de Saúde, Cópias de Comunicação de Parecer e Cópias de } \\
\text { Ata de Inspeção de Saúde. Também gerencia o arquivo e a estatística dos } \\
\text { atendimentos. }\end{array}$ \\
\hline $\begin{array}{l}\text { SISGEMS } \\
\text { Sistema de Gerenciamento } \\
\text { de Material de Saúde }\end{array}$ & $\begin{array}{l}\text { Este sistema permite o gerenciamento do estoque de material e medicamentos } \\
\text { de saúde. }\end{array}$ \\
\hline $\begin{array}{l}\text { FIGOMIS } \\
\text { Ficha de Informação Gerencial das } \\
\text { Organizações Militares de Saúde }\end{array}$ & Este sistema gerencia as atividades da Divisão de Saúde \\
\hline
\end{tabular}


Também, as atividades da Divisão de FuSEx são gerenciadas pelo sistema SIRE (Sistema de Registro de Encaminhamento). Esse sistema realiza o controle informatizado do atendimento médico-hospitalar do Sistema de Saúde do Exército (Quadro 6).

\subsection{Mapeamento do fluxo de valor atual}

A aplicação propriamente dita do conceito de Escritório Enxuto no Posto Médico deu-se primeiramente com o envolvimento de todos os colaboradores. Para coordenar essas atividades foi designado um grupo gestor multidisciplinar chamado de G5. Este grupo realizou uma série de encontros, na forma de palestras, sobre conceitos enxutos, envolvendo a recepção, os médicos, os dentistas, os colaboradores da administração, dentre outros. No momento seguinte, o grupo pode identificar o comprometimento dos envolvidos em melhor atender os usuários do Posto Médico.

Os próximos passos foram na direção de se identificar qual fluxo de valor do processo de atendimento mais representativo na organização. $\mathrm{O}$ fluxo escolhido foi o atendimento na recepção.

O mapeamento do fluxo de valor atual (VSM atual) foi elaborado (Anexo 5). Por meio dele, os primeiros resultados provenientes de sua análise, os desperdícios vieram à tona (Tabela 2).

E ainda, identificaram-se as causas interinas das disfunções do Posto Médico no atendimento à saúde dos usuários. Para se encontrar as causas raízes dessas disfunções, a seguir será apresentada uma análise complementar ao mapeamento do fluxo de valor atual.

\subsection{Disfunções da estrutura organizacional do Posto Médico}

O Posto Médico é uma estrutura que não possui autonomia administrativa, sendo totalmente dependente do Comando da Brigada para a condução de sua vida vegetativa. Esta característica naturalmente conduz a alguns conflitos de interesse (Quadro 7).

Todas as atividades de logística, apoio de informática, administração de recursos humanos, serviços gerais são controlados pelo Comando da Brigada por força da estrutura organizacional determinada pelo Comando do Exército.

$\mathrm{O}$ efetivo profissional do Posto atende somente às atividades do expediente normal. Já as atividades ininterruptas, representadas pelo serviço de plantões, são desenvolvidas por profissionais de todas as Organizações Militares da Guarnição, inclusive do próprio Posto, em regime de escala de médicos, dentistas, técnicos de enfermagem, auxiliares de saúde e motoristas de ambulância. Fatores esses nitidamente geradores de conflitos, uma vez que cada profissional tem uma forma particular de desenvolver seu trabalho e cada Organização Militar a que este profissional pertence, embora obedeça a regulamento

Quadro 6. Sistema de registro de encaminhamento (SIRE).

\begin{tabular}{|c|c|}
\hline Sistema & Descrição \\
\hline SIRE & 1. No primeiro dia do mês é disponibilizado um determinado limite de valor na conta da Unidade \\
Gestora (UG/FuSEx), com base em dados de média histórica da suas necessidades; & 2. Após a triagem, constatada a necessidade de encaminhamento a uma Organização Civil de Saúde \\
& (OCS) ou a um Profissional de Saúde Autônomo (PSA), o beneficiário dirige-se ao setor de \\
& Emissão de Guias de Encaminhamento; \\
3. Neste setor é definido o local de atendimento (OCS ou PSA) conforme disponibilidade do & sistema e preferência do beneficiário, realizado o cálculo do valor da guia, com base em valores \\
& estabelecidos em contrato e previamente cadastrados no SIRC (Sistema de Registro de Contratos), \\
após o atendimento a todos os quesitos de postura legal, conforme preceitua a Lei de Licitações e & Contratos; \\
4. A guia emitida gera um débito no saldo disponível para a UG/FuSEx; \\
5. De posse da guia, o usuário se dirige ao prestador de serviço que executa o procedimento e \\
encaminha a fatura ao setor de Auditoria de Contas Médicas que, após a conferência, confirma o \\
valor no sistema (averbação), gerando um Mapa para Pagamento ao prestador e implantando uma \\
despesa na conta do beneficiário; \\
6. Após gerado o mapa, o sistema disponibiliza crédito para pagar a despesa; \\
7. Com o crédito disponibilizado é emitida a Nota de Empenho que gera a disponibilização do \\
numerário; \\
8. Disponibilizado o numerário e de posse da Nota de Empenho e respectiva Nota Fiscal do Serviço \\
prestado, a Tesouraria emite a respectiva Ordem Bancária; \\
9. Após esse procedimento é efetivada a Liquidação da despesa.
\end{tabular}


único, também possui aspectos e características particulares. Além disso, as escalas não são fixas; assim, a cada plantão, um mesmo profissional estará trabalhando com outros com os quais eventualmente nunca trabalhou.

Não obstante, a rotatividade dos profissionais é intensa. A cada ano são licenciados mais de 50\% do efetivo de médicos e novos profissionais são incorporados. Essa característica se constitui num verdadeiro obstáculo ao estabelecimento de padrões. Os novos integrantes, quando atingem uma integração razoável com o serviço, já estão sendo licenciados e todo o processo tem que recomeçar. Devido a aspectos relacionados ao mercado de trabalho. esta rotatividade é muito menor em relação aos profissionais odontólogos, farmacêuticos, técnicos de enfermagem e auxiliares de saúde, embora tenha flutuação pouco maior em relação aos motoristas de ambulância.

A análise dessas circunstâncias deixa claro que há dificuldade em manter um padrão de atendimento e, mais que isso, infere-se a existência de conflitos internos acentuados. As solicitações de remanejamento de efetivos e de alteração da estrutura organizacional aos escalões superiores, já realizadas, mostraram-se ineficazes na resolução dos problemas.

Além disso, os sistemas corporativos necessitam de maior integração. Eles foram recentemente implantados e ainda necessitam de ajustes, pois os programas de gerenciamento têm se mostrado bastante eficazes e estão contribuindo para a melhoria de vários processos.

Na prática visam estabelecer parâmetros comuns de avaliação da gestão das organizações de saúde do Exército, em âmbito nacional, criando um ranking de melhor desempenho, forçando desta forma a procura pela melhoria contínua. Para tal, uma das maneiras de se buscar esta melhoria é implantar as ferramentas de Escritório Enxuto.

\subsection{O desdobramento do pensamento enxuto aplicado no Posto Médico}

Constatada a existência do problema, pelo VSM atual, ou seja, dos desperdícios e das disfunções, buscou-se estudá-los por todos os ângulos, procurando os pontos nos quais se poderia atuar. Esse desdobramento foi realizado por meio do mapeamento do fluxo de valor futuro (VSM futuro).

Nessa fase é muito importante definir os objetivos delineados para o desempenho do futuro processo de atendimento, identificar as medidas de desempenho, escolher as ferramentas de solução dos problemas, definir e implantar os planos de ações kaizen e acompanhar por meio de gestão à vista.

O grupo de trabalho G5, por meio da análise do mapeamento do fluxo de valor, definiu, em conjunto com os envolvidos, os seguintes objetivos:

- elevar a satisfação dos usuários no atendimento de saúde para $80 \%$;

- reforçar os níveis de satisfação dos colaboradores do Posto Médico em 40\%; e

- melhorar o posicionamento do PMGuCas na avaliação do Exército em $60 \%$.

Para se alcançar o estado enxuto, bem como os objetivos elencados, procurou-se a busca pelo Fluxo Contínuo, com a redução do lead-time. Também, elaborou-se o Trabalho Padrão por meio da Matriz de Responsabilidade.

Esse mapeamento identificou que a área em que eclodiam os conflitos era a recepção, contudo, verificava-se que o nascedouro, a origem, estava nas relações entre todas as seções do Posto Médico e deste com o seu ambiente externo. O resultado da comunicação ineficiente, falha ou inexistente, entre as seções era passada ao usuário e, logicamente, gerava insatisfação.

O problema foi apresentado ao Chefe da $1^{\text {a }}$ Seção do Estado-Maior da Brigada, gerente de recursos humanos e de qualidade, responsável pelo Projeto Família Militar, que visa justamente, entre outros

Quadro 7. Disfunções nas atividades organizacionais.

\begin{tabular}{|c|c|c|c|c|}
\hline Atividades & Posto Médico & Comando da Brigada & Disfunções & Oportunidade Enxuta \\
\hline Direção & Subcomando & Comando & Posto Médico é & VSM \\
\hline Logística e TI & Usuário & Administrador & $\begin{array}{c}\text { responsável pelo serviço } \\
\text { Comando da Brigada é } \\
\text { quem administra }\end{array}$ & $\begin{array}{l}\text { Revisão nos } \\
\text { Sistemas } \\
\text { Corporativos }\end{array}$ \\
\hline Atendimento Saúde & $\begin{array}{l}\text { Expediente } \\
\text { normal }\end{array}$ & $\begin{array}{l}\text { Expediente } \\
\text { plantão }\end{array}$ & $\begin{array}{l}\text { Maior rotatividade nas } \\
\text { áreas (área médica com }\end{array}$ & Trabalho \\
\hline Recursos Humanos & Fixo & Rotativo & maior incidência) & Padrão \\
\hline $\begin{array}{l}\text { Padronização e } \\
\text { Normatização }\end{array}$ & Média & Baixa & $\begin{array}{l}\text { Dificuldade em manter } \\
\text { plano de ações }\end{array}$ & $5 \mathrm{~S}$ \\
\hline
\end{tabular}


aspectos, a melhoria contínua nos processos ligados ao Posto Médico.

$\mathrm{O}$ gerente de recursos humanos e de qualidade avaliou junto aos seus colaboradores, qual seria a primeira ação a ser tomada, para que se pudesse desdobrar o diagnóstico atual. A opção tomada foi de se solicitar um assessoramento externo, que ocorreu pelo fato de haver uma grande resistência interna à adoção pelo Exército de novas práticas gerenciais.

Uma parceria foi realizada no ano de $2007 \mathrm{com}$ uma empresa especializada na Gestão Estratégica de Pessoas, a qual imediatamente iniciou seus trabalhos por meio de um diagnóstico no Posto Médico, identificando o ambiente organizacional, a relação de processos internos e externos (correlacionados), alinhados com a elaboração estratégica do cenário futuro desejado.

Nesse novo diagnóstico optou-se por analisar as disfunções em forma de Matriz de Responsabilidade Funcional (Tabela 1). Ela procura identificar as causas raízes (causas principais), na qual, para um dado produto ou serviço, essa matriz apresenta a interação entre o fornecedor e cliente do fluxo de um processo sistêmico, avaliando as entradas, as saídas e os feed-backs. Na matriz, foram analisadas 272 relações entre 17 áreas correlatas.

Essa matriz serve também para identificar as funções organizacionais envolvidas no processo de prestação de serviço e suas interfaces, introduzindo a lógica cliente $v s$. fornecedor na organização.

Assim, durante o ano 2008, o Posto Médico, após identificar sua Matriz, estabeleceu uma planilha sequenciada de reuniões, com os principais envolvidos nos diferentes processos, buscando ações para uma racionalização e uma padronização, bem como melhorar suas respectivas interfaces, minimizando os conflitos organizacionais, reduzindo-se e eliminando-se os trabalhos repetidos e desnecessários. A implementação dessas práticas gerenciais ficou a cargo do grupo de trabalho multidisciplinar G5, o qual se reúne periodicamente para a realização da análise crítica do andamento dos trabalhos.

A matriz da Tabela 1, apresenta nas suas células de intersecção, a quantidade de possibilidades de correlação dentro dos diversos processos existentes no PMGuCas, as quais foram elencadas por meio do conhecimento tácito dos membros do G5.

Ao final do trabalho, com a Matriz de Responsabilidade Funcional definida e acordada, o processo foi padronizado, com as relações entre as áreas da organização claramente definidas, facilitando e permitindo a aplicação de diferentes instrumentos para a eliminação dos desperdícios encontrados. Uma vez definida na matriz a relação Responsável/Funcional, os responsáveis dos processos nas diversas áreas do Posto Médico têm nessa fase do trabalho a consciência do seu papel, de seus clientes e fornecedores, bem como de suas necessidades.

Com os processos identificados de forma clara (Quadro 8), o fornecedor interno passa a entender a relação entre a necessidade de seus clientes internos e a satisfação do cliente final. Por meio do mapeamento do processo, cada relação Cliente $\times$ Fornecedor Interno passa a estar: especificada, acordada e controlada. Em uma nova postura, a responsabilidade da "Não Satisfação dos Clientes Internos" não deve ser transferida aos fornecedores.

As ações do grupo, neste novo momento com o novo modelo, buscam o aprimoramento em direção à eficácia (produto/serviço), e a eficiência (recursos), que devem

Tabela 1. Matriz de Responsabilidade Funcional (atendimento).

\begin{tabular}{ccccccccccccccc}
\hline $\mathbf{C} / \mathbf{F}$ & $\mathbf{1}$ & $\mathbf{2}$ & $\mathbf{3}$ & $\mathbf{4}$ & $\mathbf{5}$ & $\mathbf{6}$ & $\ldots$ & $\mathbf{1 1}$ & $\mathbf{1 2}$ & $\mathbf{1 3}$ & $\mathbf{1 4}$ & $\mathbf{1 5}$ & $\mathbf{1 6}$ & $\mathbf{1 7}$ \\
\hline 1 & $\mathrm{X}$ & 1 & 2 & 3 & 4 & 5 & $\ldots$ & 10 & 11 & 12 & 13 & 14 & 15 & 16 \\
2 & 17 & $\mathrm{X}$ & 18 & 19 & 20 & 21 & $\ldots$ & 26 & 27 & 28 & 29 & 30 & 31 & 32 \\
3 & 33 & 34 & $\mathrm{X}$ & 35 & 36 & 37 & $\ldots$ & 42 & 43 & 44 & 45 & 46 & 47 & 48 \\
4 & 49 & 50 & 51 & $\mathrm{X}$ & 52 & 53 & $\ldots$ & 58 & 59 & 60 & 61 & 62 & 63 & 64 \\
5 & 65 & 66 & 67 & 68 & $\mathrm{X}$ & 69 & $\ldots$ & 74 & 75 & 76 & 77 & 78 & 79 & 80 \\
6 & 81 & 82 & 83 & 84 & 85 & $\mathrm{X}$ & $\ldots$ & 90 & 91 & 92 & 93 & 94 & 95 & 96 \\
$\ldots$ & & & & & & & $\ldots$ & & & & & & 205 & $\ldots$ \\
13 & 193 & 194 & 195 & 196 & 197 & 198 & $\ldots$ & 203 & 204 & $\mathrm{X}$ & 205 & 206 & 207 & 208 \\
14 & 209 & 210 & 211 & 212 & 213 & 214 & $\ldots$ & 219 & 220 & 221 & $\mathrm{X}$ & 222 & 223 & 224 \\
15 & 225 & 226 & 227 & 228 & 229 & 230 & $\ldots$ & 235 & 236 & 237 & 238 & $\mathrm{X}$ & 239 & 240 \\
16 & 241 & 242 & 243 & 244 & 245 & 246 & $\ldots$ & 251 & 252 & 253 & 254 & 255 & $\mathrm{X}$ & 256 \\
17 & 257 & 258 & 259 & 260 & 261 & 262 & $\ldots$ & 267 & 268 & 269 & 270 & 271 & 272 & $\mathrm{X}$ \\
\hline
\end{tabular}

C/F: Cliente/Fornecedor; 1: Atendimento; 2: Dentista; 3: Laboratório; 4: Secretária; 5: Contrato; 6: Enfermagem; 7: Junta; 8: Chefia; 9: Comissão de ética médica; 10: Almoxarifado; 11: FuSEx; 12: Paciente; 13: Brigada; 14: Equipe de limpeza; 15: Emissão de guias; 16: Médicos; 17: Equipe de plantão. Este formato de matriz é utilizado nos treinamentos dos cursos da Fundação Vanzolini, São Paulo, Capital. 
ser compartilhadas entre os clientes e fornecedores internos. Nesta etapa, o comprometimento do pessoal de saúde e dos elementos das Organizações Militares da Guarnição, necessários ao bom andamento dos trabalhos, com a atividade fim do PMGuCas, foi muito importante.

No Quadro 8, encontra-se o exemplo das duas primeiras relações entre Cliente vs. Fornecedor, provenientes da Matriz de Responsabilidade Funcional. No caso Atendimento vs. Dentista não havia disfunções significativas. Já no caso Atendimento vs. Laboratório, pode-se identificar disfunções, que necessitavam de tomadas de ações.

\section{Resultados obtidos}

\subsection{Mapeamento do fluxo de valor}

A Tabela 2 apresenta os resultados do Mapeamento do Fluxo de Valor, atual (Anexo 5) e futuro. O cálculo de agrega valor saltou de $1,7 \%$ para $8,2 \%$ e o lead-time passou de 18 dias para 4 dias. Uma melhoria aproximada de cinco vezes.

\subsection{Padronização}

Não havia padrão, por exemplo, para o atendimento na recepção. Hoje ele está todo amarrado em procedimentos operacionais padrão. Inicialmente o usuário é recebido por um "atendente ativo" (recepcionista treinado), que vai ao seu encontro para orientá-lo no que este deve fazer, visando agilizar o seu atendimento. Essa padronização foi identificada com a Matriz Funcional, que permitiu que as interfaces nas relações dentro de cada processo ficassem bem nítidas e evidentes, para cada um dos participantes daquele evento. Assim, puderam ser criadas, em melhores condições, as estratégias de resolução dos problemas encontrados e conseguiu-se um maior comprometimento do grupo.

Procurou-se, por meio de processo (odontologia e LAC - Laboratório de Análises Clínicas), a eliminação de retrabalho e outros desperdícios de tempo. Como exemplo, a negociação com fornecedores, tais como protéticos e o estabelecimento de procedimentos de aferição da qualidade ao longo da produção no LAC e gabinete odontológico.

$\mathrm{O}$ pessoal da área da recepção recebeu material e treinamento em novos procedimentos para atendimento

Quadro 8. Relações entre Fornecedor e Cliente (entrada, saída,feed-back).

\begin{tabular}{|c|c|c|c|}
\hline $\mathbf{N}^{0}$ & $\begin{array}{c}\text { Fornecedor } \\
\text { Cliente }\end{array}$ & $\begin{array}{c}\text { Relacionamentos } \\
\text { (entrada, saída, feed-back) }\end{array}$ & Disfunções (conflitos) \\
\hline 01 & $\begin{array}{l}\text { Atendimento } \\
\text { Dentista }\end{array}$ & $\begin{array}{l}\text { 1. Recepção de pacientes (pessoal e telefônico) } \\
\text { 2. Informações diversas } \\
\text { 3. Agendamentos } \\
\text { 4. Abertura e encaminhamentos de prontuários }\end{array}$ & $\begin{array}{l}\text { Não identificados } \\
\text { conflitos relevantes }\end{array}$ \\
\hline 02 & $\begin{array}{l}\text { Atendimento } \\
\text { Laboratório } \\
\text { de Análises } \\
\text { Clínicas }\end{array}$ & $\begin{array}{l}\text { 1. Recepção de pacientes (pessoal e telefônico) } \\
\text { 2. Informações diversas } \\
\text { 3. Agendamentos } \\
\text { 4. Entrega de exames } \\
\text { 5. Entrega e recebimento de materiais }\end{array}$ & $\begin{array}{l}\text { 1. Recepção de pacientes acumulativo ao } \\
\text { setor recepção } \\
\text { 2. Entrega de resultados sem certificação ou } \\
\text { garantia de assinatura de entrega } \\
\text { 3. Local inapropriado para armazenamento e } \\
\text { exposição de materiais (exames) e recebidos } \\
\text { para análises clínicas. }\end{array}$ \\
\hline
\end{tabular}

Nota: Apresentam-se apenas dois exemplos; porém, no estudo de caso foram realizadas todas as correlações (272) da Matriz.

Tabela 2. Mapeamento do Fluxo de Valor atual e futuro.

\begin{tabular}{lccccccccc}
\hline & $\mathbf{1}$ & $\mathbf{5 , 7 , 9 , \mathbf { 1 1 }}$ & $\mathbf{4 , ~ 8 , ~ 1 3}$ & $\mathbf{2 , 6 , 1 6 , \mathbf { 1 1 }}$ & $\mathbf{3}$ & $\mathbf{1 0 , \mathbf { 1 5 }}$ & $\mathbf{S I R E}$ & $\mathbf{1 5}$ & VSM \\
\hline P & 1 & 4 & 3 & 1 & 1 & 2 & 1 & 1 & 14 \\
TRA (minutos) & 10 & 30 & 15 & 30 & 15 & 15 & 20 & 15 & 150 \\
TPa (dias) & 1 & 5 & 1 & 7 & 1 & 1 & 1 & 1 & 18 \\
TPf (minutos) & 10 & 60 & 480 & 960 & 30 & 240 & 15 & 30 & 1825 \\
\hline
\end{tabular}

Nomenclatura $\rightarrow$ P: número de pessoas envolvidas na atividade; TRA: tempo de realização da atividade (trabalho) em minutos; TPa: tempo de permanência na atividade atual em dias; TPf: tempo de permanência na atividade futura em minutos. Processos $\rightarrow$ SIRE: Sistema de Registro de Encaminhamento; 1: Atendimento; 2: Dentista; 3: Laboratório; 4: Secretária; 5: Contrato; 6: Enfermagem; 7: Junta; 8: Chefia; 9: Comissão de ética médica; 10: Almoxarifado; 11: FuSEx; 12: Paciente; 13: Brigada; 14: Equipe de limpeza; 15: Emissão de guias; 16: Médicos; 17: Equipe de plantão. Cálculo de agrega valor $\rightarrow$ AVatual $=150$ minutos $/ 18$ dias $=1,7 \% ;$ AVfuturo $=150$ minutos $/ 1825$ minutos $=8,2 \% ; 1$ dia $=8$ horas; Lead-time atual $=18$ dias; Lead-time futuro $=4$ dias. 
ao público, assim como os sistemas de TI (Tecnologia de Informação) foram duplicados, em todo o PMGuCas, para se evitar solução de continuidade nos canais de acesso aos diversos servidores de apoio.

Após as principais atividades estarem padronizadas, com a utilização da Matriz de Responsabilidade, foi possível a realização de um balanceamento por meio da eliminação dos gargalos encontrados.

\subsection{Motivação}

A questão da motivação sempre representou um grande óbice, pois eventualmente gerava a saída de um ou outro especialista, tanto na área médica quanto na área odontológica. Hoje esta questão já está resolvida com a elevação significativa da taxa de permanência dos profissionais. Por meio do trabalho com a matriz, durante as reuniões, para estabelecê-la, procurou-se aparar alguma aresta e, com a vinda dos resultados esperados, pode-se motivar a equipe como um todo. O monitoramento desse aspecto foi por meio de uma pesquisa de clima organizacional semestral e, como resultado, mostrou-se que a satisfação da equipe passou de 30 para $70 \%$, segundo os últimos dados.

\subsection{Fluxo}

A eliminação de atividades que não agregavam valor ao serviço prestado e o melhor aproveitamento do tempo disponível permitiu que o esforço fosse direcionado nas atividades específicas de atendimento ambulatorial, laboratorial e odontológico, os quais passaram a ser realizados em fluxo contínuo, gerando a redução da espera nos agendamentos para consultas, entre outros aspectos. Visando reduzir o tempo no processo, que passou de 30 dias para 10 dias em média, de encaminhamento para consultas externas, pois é necessário a troca do formulário de encaminhamento do FuSEx por uma guia do plano da rede civil conveniada, foram colocados dentro do PMGuCas atendentes, os quais processavam de imediato a referida troca.

Neste ponto, um melhor compartilhamento dos equipamentos de maior demanda e dos consultórios usados em sistema de rodízio pelas diversas especialidades médicas foi muito significativo para uma melhora geral do sistema como um todo. Com a existência de um só consultório para ser compartilhado por dois especialistas ou dentistas decidiu-se que, visando diminuir o tempo de espera, o atendimento seria até às 22 horas e não mais até às 18 horas.

\subsection{Apoio}

Com a remodelagem, baseada no Escritório Enxuto, dos diferentes processos encerrada, foram viabilizadas ações consistentes de melhoria nos diversos serviços prestados pelo PMGuCas, haja vista que as atividades de apoio começaram a fluir de forma adequada com reflexos positivos no atendimento e no aumento da motivação de todos os profissionais. Como exemplo, o repasse de recursos financeiros, de materiais e o atendimento de solicitações de serviços de manutenção necessários ao bom funcionamento do sistema eram deficientes. No caso do fornecimento de materiais de limpeza e de consumo geral, os quais só eram disponibilizados com prazos que variavam de 60 a 90 dias passaram ser fornecidos mensalmente. O mesmo pode-se dizer do atendimento a solicitações de suporte e manutenção em TI, que passou de uma semana para o pronto atendimento.

Quanto ao estabelecimento de convênios com hospitais civis e profissionais autônomos que suplementam as demandas dos usuários, parcerias desejadas ou perdidas ao longo do tempo, foram estabelecidas com sucesso ao longo do ano de 2008, principalmente com hospitais da região. No caso de hospitais, clínicas e laboratórios (OCS) houve anteriormente uma queda de oito entidades para uma e posteriormente uma recuperação para nove. E, em relação aos médicos, fisioterapeutas, dentistas, psicólogos e nutricionistas (PSA), houve uma queda de doze entidades para três, e uma recuperação para quinze. Um destaque foi o caso de um importante hospital de Campinas que espontaneamente procurou a direção do Posto para o fechamento de um contrato, o qual está em processo final de homologação pela $2^{a}$ Região Militar.

Importante citar o aumento de patrocinadores, dentro do segmento médico da cidade, para a realização de eventos de apoio social e campanhas de saúde desenvolvidas nos últimos dois anos. O principal destaque é a uma empresa de medicamentos do estado de São Paulo e há ainda hospitais e planos de saúde da região com um sucesso de $40 \%$ para $60 \%$. As campanhas junto a órgãos públicos e privados (Prefeituras e shoppings, por exemplo) alcançou-se de $15 \%$ para $45 \%$.

\subsection{Ranking}

Outro aspecto a ser relatado foi o da elevação da pontuação do PMGuCas no ranking de alguns sistemas corporativos utilizados para a gestão da área de saúde no Exército, citados neste artigo. Principalmente no SIRE, que estabelece, na Diretoria de Saúde em Brasília, por meio de indicadores que estão alinhados com um BSC (painel de controle) do Exército, vide Anexo 6, neste caso na dimensão das atividades internas ligadas a família militar. Nessa análise o posto veio a ocupar, quatro meses após a implantação 
das melhorias, a segunda posição dentre vinte e um postos espalhados pelo território nacional, depois de passar alguns anos ocupando posições que flutuavam pelo terceiro tercil do ranking (da $15^{\mathrm{a}}$ posição para a $2^{\mathrm{a}}$ posição, ou seja, $90 \%$ de melhoria). Esta conquista permitiu um maior aporte, aumento em torno de 55\%, de recursos financeiros do sistema do Fundo de Saúde do Exército, em função de uma acentuada elevação na produção ambulatorial, laboratorial e clínica. Esta situação é função operacional do próprio sistema e pode ser consultada pela internet (on line), por meio de senha eletrônica.

Os demais sistemas que são utilizados também foram beneficiados e é intuito do Comando da Guarnição fazer do PMGuCas uma referência não só para a área militar como também para outras organizações semelhantes no meio civil. Como a matriz permeou todas as atividades dentro do PMGuCas, os sistemas ligados ao patrimônio (SISGEMS - Sistema de Gerenciamento de Material de Saúde), as perícias médicas e outros foram beneficiados. O SIRC (Sistema de Registros de Contratos) foi o principal deles, pois está intimamente ligado ao SIRE (Sistema de Registro de Encaminhamento).

\subsection{Satisfação}

Por fim, as pesquisas de satisfação, por meio de caixa de sugestões e questionários para usuários, realizadas após cada atendimento, vêm apresentando uma melhora muito importante, de $40 \%$ para $85 \%$, com a adoção dessas ferramentas gerenciais, a partir das quais são adotadas ações que suportam os padrões de qualidade impostos pelo Exército e, principalmente, pelo usuário final. Essa conduta foi suportada pela disciplina e envolvimento do $5 \mathrm{~S}$. Os parâmetros que suportam a satisfação estão ligados à conduta do profissional na recepção e na consulta interna e externa com a disponibilização de serviços.

\section{Conclusões}

Definidas as causas do problema existente, com a perfeita definição dos limites dos processos que envolvem o PMGuCas, buscou-se estudá-las por todos os ângulos, procurando-se os pontos em que se poderia atuar. A área em que eclodiam os conflitos, de forma visível, era a da recepção. Contudo foi identificado que isto acontecia por consequência de outras áreas que se correlacionavam com a do primeiro atendimento, como as de suporte administrativo, do serviço de plantão e tantas outras, sem contar a grande interação da estrutura organizacional do PMGuCas com as demais organizações militares da guarnição, e por serem seus integrantes, além de gestores, usuários também.

Antes da adoção do pensamento enxuto, o PMGuCas seguia um modelo gerencial que privilegiava uma postura estanque em cada um dos envolvidos nos diversos processos. Fruto disso, por exemplo, as requisições de material (particularmente ambulatorial, laboratorial e de próteses dentárias) eram feitas sem um planejamento de necessidades efetivas, de maneira centralizada, o que gerava um inventário ocioso e consequentemente antecipava um desembolso financeiro desnecessário, inviabilizando o atendimento a outras necessidades importantes em um determinado momento.

A metodologia utilizada no Posto Médico fez uso dos princípios do Escritório Enxuto e hoje o PMGuCas tem, com os seus OCS (Organizações Civis de Saúde), PSA (Profissionais de Saúde Autônomos) e fornecedores, uma forte relação de parceria, em que os sucessos e os óbices são compartilhados. O mesmo ocorre no ambiente interno, nas relações dos responsáveis pelos vários processos. O usuário, também, tem uma visão mais clara das reais possibilidades de atendimento e, com isso, seu nível de ansiedade foi reduzido.

Os resultados decorrentes das ações kaizen iniciaram-se com a ferramenta Trabalho Padrão, que recebeu todas as informações decorrentes da Matriz Responsabilidade e com o apoio da ferramenta 5S, levou-os ao sucesso alcançado. Isso só foi possível pelo envolvimento e comprometimento de todo o corpo clínico e suporte, cuja satisfação de equipe alcançou melhores resultados. Já o Mapeamento de Fluxo de Valor pode focalizar os gargalos, destacando-se o atendimento odontológico e protético e o agendamento de consultas, enquanto as áreas de apoio melhoraram substancialmente, desde o fornecimento de materiais de limpeza até o atendimento à solicitação em TI. Esses resultados fizeram com que o PMGuCas alcançasse as primeiras posições dentre todos os Postos Médicos do Exército Brasileiro.

O resultado alcançado com a aplicação no Posto Médico dos princípios enxutos, com certeza continuará trazendo benefícios para todos, como: melhoria do atendimento aos clientes externos (usuários), maior postura profissional e humana para os envolvidos no processo interno, melhoria no modelo gerencial, maior credibilidade com os fornecedores e, consequentemente, o evidenciamento e reconhecimento da missão da organização por todos os seus integrantes.

Alguns indicadores internos, monitorados por meio do BSC, que ocorre em nível da instituição, estão sendo trabalhados, alimentados por estas pesquisas e, futuramente, com certeza, irão corroborar esta tendência de melhora. Isto é vital para que se materialize o caráter da efetividade em todas as ações.

Finalmente, pode se responder às perguntas iniciais da pesquisa. A Matriz de Responsabilidade pode equacionar e solucionar as diferenças de 
cultura gerencial de pessoas da área de saúde com a administração. E ainda, o Mapeamento de Fluxo de Valor colaborou substancialmente na prospecção e redução do lead-time.

Logicamente este trabalho será permanente, uma vez que a busca pela qualidade é incessante e só é viável por meio da melhoria contínua.

\section{Referências}

AHLSTROM, P. Lean service operations: translating lean production principles to service operations. International Journal of Service Technology and Management, v. 5, n. 5/6, p. 545-566, 2004.

DENNIS, P. Produção lean simplificada. Porto Alegre: Bookman, 2007.

EHRLICH, B. H. Transactional six sigma and lean servicing: leveraging manufacturing concepts to achieve world-class service. London: CRC Press, 2002.

FABRIZIO, T.; TAPPING, D. 5 S for the office: organizing the work place to eliminate waste. New York: Productivity Press, 2006.

GEORGE, M. L. Lean seis sigma para serviço. Rio de Janeiro: Qualitymark, 2004.

GIL, A. C. Gestão de pessoas: enfoque nos papéis profissionais. São Paulo: Atlas, 2001.

HINES, P.; TAYLOR, D. Going lean: a guide to implementation. Cardiff: Lean Enterprise Research Center, 2000.

KIM, C. S. et al. Lean health care: what can hospitals learn from a word-class automaker? Journal of Hospital Medicine, v.1, n. 5, p. 191-199, 2006.

LARAIA, A. C.; MOODY, P. E.; HALL, R. W. The Kaizen blitz: breakthrough in productivity and performance. New York: John Willey, 1999.

LAREAU, W. Office Kaizen: transforming office operations into a strategic competitive advantage. Milwaukee: ASQ Quality Press, 2002.

LEWIS, M. A. Lean production and sustainable competitive advantage. International Journal of Operations \& Production Management, v. 20, n. 8, p. 959-978, 2010.

LIKER, J. K. The Toyota way: 14 management principles from the world's greatest manufacturer. New York: McGraw-Hill, 2004.

LIMA, A. C., PINSETTA, W. J. M., LIMA, P. C. Mapeamento da cadeia de valor na divisão de suprimentos do hospital de clínicas da UNICAMP para redução do lead time no processo de aquisição de materiais hospitalares. In: ENCONTRO NACIONAL DE ENGENHARIA DE PRODUÇÃO, 25., 2005, Porto Alegre. Anais... Porto Alegre: ENEGEP, 2005. p. 1708-1714.

MANN, D. Creating a lean culture: tools to sustain lean conversions. New York: Productivity Press, 2005.

MARCONI, M. A., LAKATOS, E. M. Técnicas de pesquisa: planejamento e execução de pesquisas, amostragens e técnicas de pesquisas, elaboração, análise e interpretação de dados. São Paulo: Atlas, 2002.

McMANUS, H. Product development value stream analysis and mapping manual (PDVMS): Alpha Draft: Lean Aerospace Initiative. Cambridge: Massachusetts Institute of Technology, 2003.

McPHERSON, J. R.; MITCHELL, A. V. 2005. Lean cousine: the mckinsey quarterly. Disponível em: <www. mckinsey.com>. Acesso em: 06 de fev. de 2010.

MEIER, H. S.; FORRESTER, P. L. A model for evaluating the degree of leanness of manufacturing firms. Integrated Manufacturing Systems, v. 13, n. 2, p. 104-109, 2002.

MIYAKE, D. I.; RAMOS, A. W. Lean Six-Sigma: brazilian experience. In: MRUDULA, E. (Org.). Lean Six Sigma: an introduction. Hyderabad: ICFAI University Press, 2007. p. 156-181.

MURGAU, A.; JOHANSSON, B.; PEJRYD, L. A study in the interaction between physical and information flows in manufacturing systems. In: THE INTERNATIONAL SEMINAR ON MANUFACTURINGS SYSTEMS, 38. 2005, Florianópolis. Anais... Florianópolis: UFSC, 2005.

OLIVEIRA, J. D. Escritório enxuto Lean Office São Paulo. 2007. Disponível em: <http://www.lean.org. br>. Acesso em: 02 de fev. de 2010.

PICCHI, F. A. Lean na administração. In: LEAN SUMMIT BRASIL, 2002, Gramado. Apresentações... Gramado: Lean Institute Brasil, 2002.

PIERCY, N.; RICH, N. Lean transformation in the pure service environment: the case of the call center. International Journal of Operations \& Production Management, v. 29, n. 1, p. 54-76, 2009.

ROTHER, M.; SHOOK, J. Aprendendo a enxergar: mapeando o fluxo de valor para agregar valor e eliminar o desperdício. São Paulo: Lean Institute Brasil, 2003.

SHAH, R.; WARD, P. T. Lean manufacturing: context, practice bundles, and performance. Journal of Operations Management, v. 21, n. 2, p. 129-149, 2003.

TAPPING, D.; SHUKER, T. Value stream management for the lean office: 8 steps to planning, mapping, and sustaining lean improvements in administrative areas. Florence: Productivity Press, 2003.

TURATI, R. C.; MUSETTI, M. A. Aplicação dos conceitos de Lean Office no setor administrativo. In: ENCONTRO NACIONAL DE ENGENHARIA DE PRODUÇÃO, 26., 2006, Fortaleza. Anais... Fortaleza: ENEGEP, 2006. p. 1-9.

WOMACK, J. P.; JONES, D. T. A mentalidade enxuta nas empresas: elimine o desperdício e crie riqueza. Rio de Janeiro: Campus, 2004.

WOMACK, J. P.; JONES, D. T.; ROOS, D. A máquina que mudou o mundo. Rio de Janeiro: Campus, 2001.

YIN, R. K. Estudo de caso: projeto e métodos. Porto Alegre: Bookman, 2005. 
Anexo 1. Desperdício de processamento no Escritório (adaptado de LAREAU, 2002).

\begin{tabular}{|c|c|}
\hline Item & Escritório \\
\hline \multirow{7}{*}{$\begin{array}{l}\text { Processo } \\
\text { Processamento } \\
\text { sem valor }\end{array}$} & $\begin{array}{l}\text { Estratégia: é o valor perdido ao implementar processos que satisfazem objetivos de curto prazo, } \\
\text { mas que não agregam valor às partes interessadas. }\end{array}$ \\
\hline & $\begin{array}{l}\text { Alinhamento de objetivos: é a energia gasta por pessoas trabalhando com objetivos desfocados e } \\
\text { o esforço necessário para corrigi-los. }\end{array}$ \\
\hline & $\begin{array}{l}\text { Estrutura: ocorre quando comportamentos existentes, expectativas, procedimentos e prioridades } \\
\text { não estão orientandas para a redução de desperdícios. }\end{array}$ \\
\hline & $\begin{array}{l}\text { Gestão estratégica de pessoas: quando existe muita diferença entre a estrutura organizacional da } \\
\text { empresa, comparada com uma organização de excelência. }\end{array}$ \\
\hline & $\begin{array}{l}\text { Padronização: é a energia gasta por causa de um trabalho não ter sido realizado da melhor forma } \\
\text { possível, de tal sorte que cada grupo quer realizá-lo à sua maneira. }\end{array}$ \\
\hline & $\begin{array}{l}\text { Processos informais: ocorrem quando recursos são usados para criá-los e mantê-los, substituindo } \\
\text { os processos oficiais. }\end{array}$ \\
\hline & $\begin{array}{l}\text { Falta de integração: é o esforço necessário para transferir informações dentro de uma } \\
\text { organização (departamento ou grupos) que não estão completamente integradas à cadeia de } \\
\text { processos utilizados. }\end{array}$ \\
\hline
\end{tabular}

Anexo 2. Desperdícios de estoque e de qualidade no Escritório (adaptado de LAREAU, 2002).

\begin{tabular}{|c|c|}
\hline Item & Escritório \\
\hline $\begin{array}{l}\text { Estoque } \\
\text { Super produção }\end{array}$ & $\begin{array}{l}\text { Alteração: é o esforço requerido para alterar dados, formatos e relatórios entre passos de um } \\
\text { processo. } \\
\text { Checagens desnecessárias: é o esforço usado para inspeções e retrabalhos. }\end{array}$ \\
\hline $\begin{array}{l}\text { Estoque } \\
\text { Inventário }\end{array}$ & $\begin{array}{l}\text { Inventário: são todos os recursos aplicados a um serviço (front office) } \\
\text { antes dele ser requerido. } \\
\text { Fluxo irregular: recursos investidos em informações que se acumulam } \\
\text { entre as estações de trabalho. }\end{array}$ \\
\hline $\begin{array}{l}\text { Qualidade } \\
\text { Defeito }\end{array}$ & $\begin{array}{l}\text { Variabilidade: são recursos utilizados para compensar ou corrigir } \\
\text { resultados que variam do esperado. } \\
\text { Confiabilidade: é o esforço necessário para corrigir resultados imprevisíveis } \\
\text { devido a causas desconhecidas. } \\
\text { Informação perdida: ocorre quando recursos são requeridos para reparar ou compensar as } \\
\text { consequências da falta de informações. } \\
\text { Cinco Esses: A resistência às mudanças leva a organização a não alcançar a Disciplina. Este fato } \\
\text { está ligado ao não cumprimento dos procedimentos, } \\
\text { ocorrendo falhas nos sistemas. }\end{array}$ \\
\hline
\end{tabular}

Anexo 3. Desperdícios de fluxo no Escritório (adaptado de LAREAU, 2002).

\begin{tabular}{|ll|}
\hline \multicolumn{1}{|c|}{ Item } & \multicolumn{1}{c|}{ Escritório } \\
\hline Fluxo & $\begin{array}{l}\text { Transporte: todo transporte de informações, exceto aqueles utilizados } \\
\text { para entregar serviços aos clientes. }\end{array}$ \\
Fluxo & $\begin{array}{l}\text { Padronização: é o movimento excessivo do esforço perdido em movimentações desnecessárias. } \\
\text { Falta de foco: ocorre toda vez que a energia e a atenção de um colaborador não estão voltadas } \\
\text { Movimentação }\end{array}$ \\
$\begin{array}{l}\text { para os objetivos estratégicos da organização. } \\
\text { Cinco esses: é a desorganização do ambiente de trabalho. }\end{array}$ \\
Fluxo & $\begin{array}{l}\text { Espera: é o recurso perdido enquanto pessoas esperam por informações, } \\
\text { reuniões, aprovações ou telefonemas. }\end{array}$ \\
\hline
\end{tabular}


Anexo 4. Sistemas corporativos de apoio.

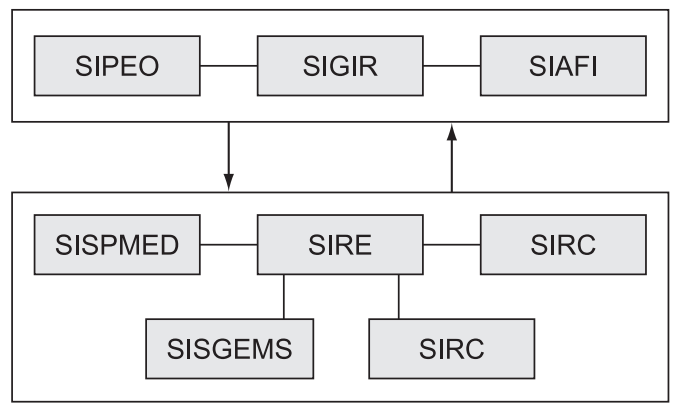

SIGIR: Sistema Integrado de Gestão Inteligente de Recursos; SIPEO: Sistemas Públicos de Planejamento e Execução Orçamentária; SIAFI: Sistemas de Administração e de Fiscalização de Pagamento; SIRE: Sistema de Registro de Encaminhamento; SIRC: Sistema de Registro de Contratos; SISPMED: Sistema de Perícias Médicas; SISGEMS: Sistema de Gerenciamento de Material de Saúde; FIGOMIS: Ficha de Informação Gerencial das Organizações Militares de Saúde.

Anexo 5. Mapeamento do fluxo de valor atual interno do PMGuCas.

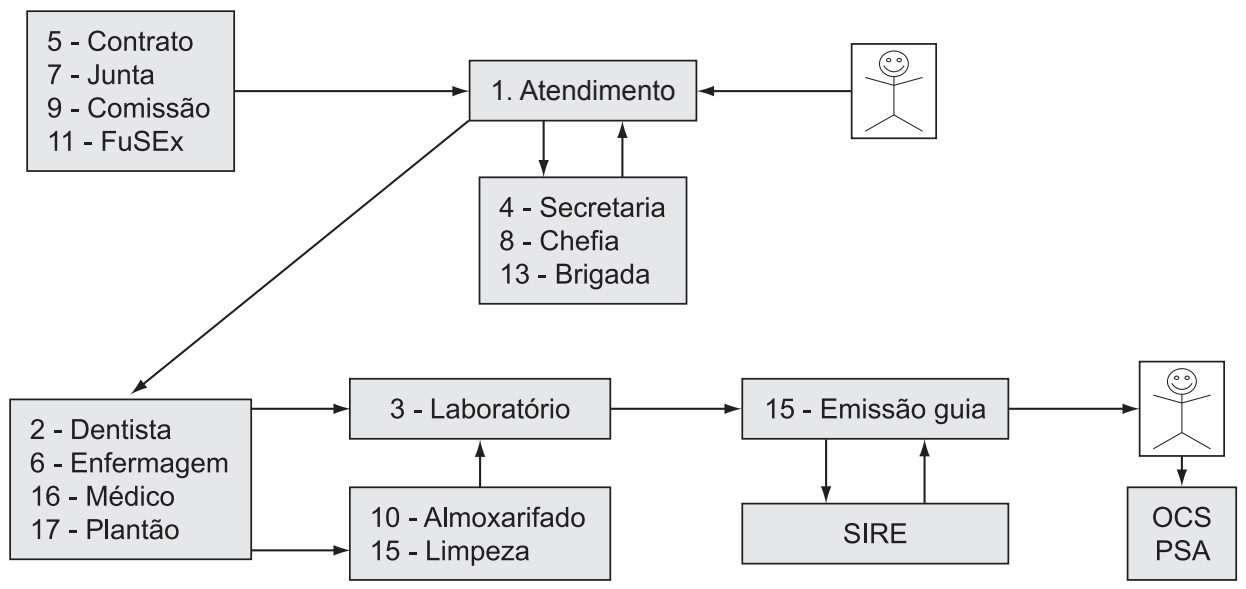

\begin{tabular}{lccccccccc}
\hline & $\mathbf{1}$ & $\mathbf{5 , 7 , 9 , \mathbf { 1 1 }}$ & $\mathbf{4 , 8 , 1 3}$ & $\mathbf{2 , 6 , 1 6 , 1 1}$ & $\mathbf{3}$ & $\mathbf{1 0 , 1 5}$ & $\mathbf{S I R E}$ & $\mathbf{1 5}$ & VSM \\
\hline $\mathrm{P}$ & 1 & 4 & 3 & 1 & 1 & 2 & 1 & 1 & 14 \\
TRA (minutos) & 10 & 30 & 15 & 30 & 15 & 15 & 20 & 15 & 150 \\
$\mathrm{TPa}$ (dias) & 1 & 5 & 1 & 7 & 1 & 1 & 1 & 1 & 18 \\
\hline
\end{tabular}

Nomenclatura $\rightarrow$ P: número de pessoas envolvidas na atividade; TRA: tempo de realização da atividade (trabalho) em minutos; TPa: tempo de permanência na atividade atual em dias; OCS (Organizações Civis de Saúde); PSA (Profissionais de Saúde Autônomos). 
Anexo 6. Sistema de avaliação do Exército Brasileiro (EB) do desempenho e qualidade dos serviços de saúde (metodologia de cálculo) (Fonte: Exército Brasileiro).

\begin{tabular}{|c|c|c|}
\hline Indicador & Subindicador & Fórmula \\
\hline \multirow[t]{4}{*}{ Desempenho } & $\begin{array}{l}\text { Eficácia: com foco no resultado orientado } \\
\text { pelas metas estabelecidas. }\end{array}$ & $\begin{array}{l}\text { (número de Militares ou Civis previstos/ } \\
\text { número de Militares ou Civis atendidos) } \times 100\end{array}$ \\
\hline & $\begin{array}{l}\text { Eficiência: com foco no processo orientado } \\
\text { pelos recursos programados. }\end{array}$ & $\begin{array}{l}\text { (número de Militares ou Civis planejados/ } \\
\text { número de Militares ou Civis atendidos) } \times 100\end{array}$ \\
\hline & $\begin{array}{l}\text { Financeiro: referencial crítico que permite } \\
\text { acompanhar o emprego dos recursos. }\end{array}$ & $\begin{array}{l}\text { (recursos programados/ } \\
\text { recursos executados }) \times 100\end{array}$ \\
\hline & $\begin{array}{l}\text { Impacto: medição do } \\
\text { resultado do trabalho final. }\end{array}$ & $\begin{array}{l}\text { (número de militares ou civis atendidos/ } \\
\text { número de militares ou civis do } \mathrm{EB} \text { ) } \times 100\end{array}$ \\
\hline \multirow[t]{3}{*}{ Qualidade } & $\begin{array}{l}\text { Qualidade intrínseca do processo } \\
\text { (Números de erros). }\end{array}$ & $\begin{array}{l}\text { (número de operações de erros/ } \\
\text { número de operações realizadas) } \times 100\end{array}$ \\
\hline & Atendimento. & $\begin{array}{l}\text { número de atendimentos realizados por } \\
\text { qualquer meio (fax, telefone, correio } \\
\text { eletrônico e contato pessoal) }\end{array}$ \\
\hline & $\begin{array}{l}\text { Segurança: uso dos mecanismos de segurança } \\
\text { que garantem a integridade da informação. }\end{array}$ & $\begin{array}{l}\text { (número de operações de controle/número de } \\
\text { operações realizadas) } \times 100\end{array}$ \\
\hline
\end{tabular}

SISPEG (Programa de Excelência do Exército) $\rightarrow$ A $1^{\text {a }}$ versão em rede, com acesso via Internet, permite o gerenciamento dos Planos de Gestão, Autoavaliação, Validação, Melhores Práticas de Gestão, Relatórios, Banco de Melhores Práticas, Cadastro da OM, Cadastro do Assessor de Gestão, Visão Sistêmica das 664 OM. Contribui com o Sistema de Medição de Desempenho Organizacional (SMDO/BSC), alinhando os Indicadores de Desempenho Operacionais e Estratégicos das OM de nível Batalhão/Subunidade até os seus respectivos Comandos Militares de Área.

SE-EB (Sistema de Excelência no Exército Brasileiro) $\rightarrow$ A Portaria № 220, de 20 de Abril de 2007 do Comandante do Exército, EstabeleceuoSistemadeExcelêncianoExércitoBrasileiro(SE-EB), emcontinuidade ao ProgramaExcelênciaGerencial(PEG-EB), implantadonoExército Brasileiro, noperíodo de 2003 a2006, conforme a Portaria do Comandante doExército No 191, de 17 de abril de 2003.

A implantação do SE-EB visa integrar as informações gerenciais do Exército Brasileiro, para auxiliar as decisões do Comandante do Exército e do Alto-Comando do Exército, incorporando os conceitos e práticas adotadas pelo PEG-EB. O SE-EB está baseado em quatro projetos principais: a) Projeto Sistema de Gestão Estratégica/Balanced Scorecard (SGE/BSC); b) Projeto Sistema Integrado de Gestão (SIG); c) Projeto de Gestão por Processos (PGP); e d) Projeto de Consolidação do PEG-EB. 